\title{
Understanding Informal Communication in Multilingual Contexts
}

\author{
Chien Wen Yuan ${ }^{1}$, Leslie D. Setlock ${ }^{1}$, Dan Cosley ${ }^{2}$, Susan R. Fussell ${ }^{1,2}$ \\ Departments of Communication ${ }^{1}$ and Information Science ${ }^{2}$ \\ Cornell University \\ \{cy294, 1ds87,drc44, srf72\}@cornell.edu
}

\begin{abstract}
Informal communication in organizations has many benefits, but people who are not native speakers of the organization's common language may find it hard to interact informally. In an interview study of nine native English-speaking and 33 non-native English-speaking students at a large U.S. university, we explore how native language shapes patterns of informal interaction. We found that non-native speakers generally preferred interacting informally with fellow speakers of their own native language as opposed to native English speakers, which hinders communication and collaboration between groups. Three factors led to this "clustering" effect: issues of common ground, feelings of social obligation to other speakers of one's native language, and desires to build social networks within a language group. Four factors led to greater motivation for cross-language interaction: a desire to build bridging capital, physical proximity, oneon-one or small-group interaction, and an established work relationship. The findings suggest ways that communication tools might reduce barriers to informal interaction between speakers of different native languages.
\end{abstract}

\section{Author Keywords}

Informal communication; cultural differences; multilingual communication

\section{ACM Classification Keywords}

H.5.m. Information interfaces and presentation (e.g., HCI): Miscellaneous.

\section{INTRODUCTION}

Informal communication in organizations has many benefits, including the development of new interpersonal relationships, awareness of others' activities, and information exchange [22, 31]. For example, researchers might find new collaborators, or students may discover job possibilities. However, people may be fluent enough to work in a multicultural organization yet be limited in their

Permission to make digital or hard copies of all or part of this work for personal or classroom use is granted without fee provided that copies are not made or distributed for profit or commercial advantage and that copies bear this notice and the full citation on the first page. To copy otherwise, or republish, to post on servers or to redistribute to lists, requires prior specific permission and/or a fee.

CSCW '13, February 23-27, 2013, San Antonio, Texas, USA. Copyright 2013 ACM 978-1-4503-1331-5/13/02...\$15.00. comfort with colloquial, spontaneous conversation. In this case, they may choose instead to interact with fellow speakers of their own native language during breaks, meals, and social events. This splintering or clustering effect could create barriers to relationship development, awareness and information exchange between speakers of different native languages. The goals of this paper are to understand how native language shapes patterns of informal interaction in an English-speaking organization for both native and non-native speakers and to identify opportunities for designing new tools to facilitate multilingual interaction in organizations.

As global organizations increasingly bring together people from around the world to work on common problems [15, $32,45]$, they face challenges due to linguistic diversity. Similarly, in educational contexts, students from around the world work together in labs, in departments, and on campus. In such contexts, problems have been shown to arise from differences in communication styles [e.g., 3, 45], relationship norms [e.g., 23, 37], negotiation strategies [e.g.,1], methods of dealing with conflict [e.g., 37], preferred media [36], and technological proficiency [e.g., 18 ], which can result in misattribution of others' intentions [14] and difficulty establishing trust [28].

Multilingual organizations can use a variety of strategies to support communication among members, including human and machine translation, selection of a common language (lingua franca) such as English, and intensive language training for all employees [21]. Choosing English as a common language is frequently the strategy of choice for many reasons, including the role of English in higher education, colonization, political considerations, and cultural influence [e.g., 50]. Using a common language reduces the need for expensive human or machine translation, while effective language training means that, in principle, no members of the organization should be marginalized because of their native language.

However, there is evidence that speaking a common language can have negative consequences for non-native speakers. Non-native speakers may fear appearing incompetent if they seem to misunderstand conversational partners, and therefore may not request needed clarification $[25,39]$. People may form within-language cliques [9, 35, 49] for the ease of conversational grounding, as in Figure 1. Non-native speakers may also lack culturally specific 
knowledge needed to engage in informal communication that is fundamental to maintaining awareness, developing relationships, and coordinating activities on the fly [35, 49]. At the same time, native speakers may be hesitant to engage in informal communication with non-native speakers because of concerns about the addressee's fluency, creating further clustering [e.g., 5, 25, 56].

In this paper, we explore the effects of using English as a lingua franca in a multilingual U.S. academic environment on both native and non-native English speakers. We first review what the literature on informal communication in organizations says about the effects of being a non-native speaker on such communication. Then, we describe and report on themes from an in-depth interview study with interviewees from a variety of linguistic backgrounds. Non-native speakers formed the within-language cliques reported by other studies, and for some of the same reasons of language fluency and lack of cultural common ground.

However, non-native interviewees also provided a number of novel insights about forces that both pushed them away from interaction with native English speakers, such as the large size and rapid conversational pace of many informal group settings, and pulled them toward interaction with members of their own language community, such as feelings of social obligation. For native English speakers, not knowing other cultures' norms for appropriate interaction pushed them away from cross-cultural communication. Interviewees also identified conditions that promoted greater informal interaction between native and non-native speakers, including personal career motivations and proximate, structured opportunities for interaction.

These forces affected participants' choices around informal multi-lingual interaction at multiple levels: individual-level forces that affected the development of relationships with specific people, group-level forces that shaped decisions about which group of people to interact with, and interaction-level forces that hindered informal communication in the moment. Thus, we close by exploring ways to use and adapt existing technologies to reduce barriers at each of these levels, with the goal of giving both native and non-native speakers more flexibility in meeting their needs around cross-lingual and crosscultural communication in organizations.

\section{BACKGROUND}

\section{Informal Communication}

In collocated organizations, informal interactions in such places as cafeterias and hallways are essential for promoting awareness of others' activities [e.g., 22, 31] and building valuable interpersonal ties [13]. The ability to converse socially is important for developing trust [28] and establishing shared identity and context [27].

However, studies suggest that informal interaction may be challenging for less fluent individuals, whose language training may have focused on task-related terminology.
These individuals may communicate well in formal situations such as meetings but have difficulty with the casual chitchat that is essential for informal information exchange and relationship development [25, 34, 49, 51].

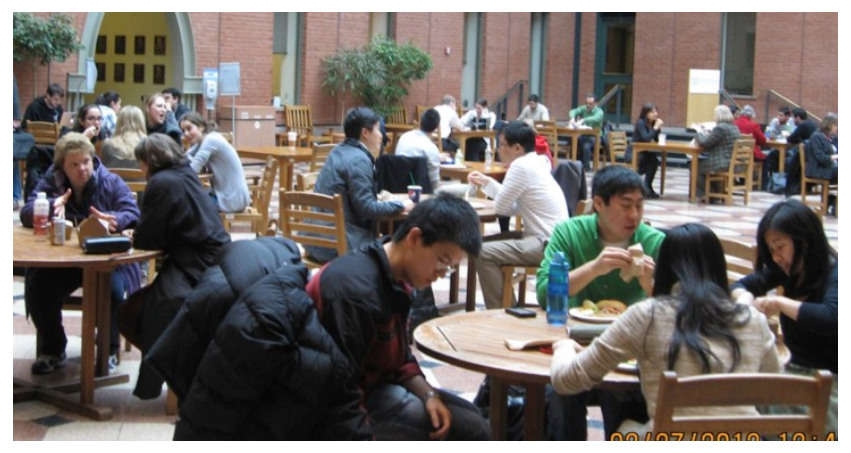

Figure 1. Clustering by language (left, English; right, Chinese) in a campus social space.

Costs of Speaking a Non-Native Language

Formal knowledge of a non-native language does not always lead to successful communication in that language. Processing messages in a foreign language imposes direct costs, decreasing the cognitive resources available for a task [47, 48]. Perceived communication competence can also affect people's willingness to communicate. Those who perceive themselves deficient in speaking a non-native language might experience anxiety in social settings, which might lead to less willingness to communicate and a lower frequency of communication [35, 53].

Not communicating, however, also has costs. English fluency is a major source of power in multilingual teams, affecting negotiations, debate, and other job functions [e.g., 36]. Misunderstandings related to non-native language use also lead to reduced trust [26] and poorer interpersonal relationships within the workplace $[10,16,43]$.

\section{Non-Native Speakers May Avoid Informal Communication}

Research suggests that less fluent individuals may hold back from participating in conversations in an effort to manage their self-presentation [5, 39]. For example, Tange and Lauring's study of a multilingual Danish firm in which English was the corporate language found that non-native English speakers reported shunning "non-essential" interactions in English [49].

Research also suggests that people who are less fluent in a non-native language prefer communicating more formally via email rather than spontaneously via IM so that they can carefully construct their thoughts $[44,45]$. This behavior, while adaptive, reduces their ability to coordinate on the fly with fellow members of the organization. It is also not a feasible strategy in many face-to-face informal settings.

Further, native language based subgroups or cliques may develop [34, 49]. In organizations that use English as a common language, non-native employees often use their native language for informal talk at meals and other social occasions, excluding those who speak the common 
language [9, 49] while failing to build their own English skills. This avoidance of informal conversation in the lingua franca is problematic because the network ties and information exchange that informal communication facilitates stay bounded within language communities or are channeled through a fluent bilingual speaker [2].

\section{THE CURRENT STUDY}

The goal of the current study is to explore in depth the factors that affect how people interact informally within and across language groups. By understanding these factors, we hoped to develop new design ideas for tools to support informal communication in multilingual organizations. We focused on students studying at a large U.S. university because in 2009 there were more than 250,000 foreign students studying in the U.S. in the areas of science and engineering alone [5]. As a result, classes, academic research labs, and other campus activities are likely to include students, faculty, and post-doctoral fellows from a variety of linguistic backgrounds.

\section{METHOD}

\section{Participants}

We recruited 42 interviewees through student mailing lists and international student associations at a large, culturally diverse university in the northeastern U.S. (23 male, 19 female). We had a total of nine English speakers and 33 non-native English speakers from China (11), Taiwan (9), South Korea (9), Japan (1), Thailand (1), Indonesia (1), and Nepal (1) who had been in the U.S. for less than five years. We focused on a sample of East Asians, which provides a valuable complement to prior research conducted in Finnish and Danish companies [e.g., 4, 20] and it is representative of many current real-world multilingual groups. Students from China, Taiwan, and South Korea comprise the three largest international student groups at the school, and interviewees from these countries had a sizeable population of fellow students who spoke the same native language. The students from Japan, Thailand, Indonesia, and Nepal were part of relatively small populations of native speakers. (There are also a significant number of Indian students, but they were not included in the study due to the extensive study of the English language in Indian educational systems.)

Interviewees were studying in a wide variety of fields, including Engineering, Economics, Architecture, Business, Anthropology, Statistics, Biology, Philosophy, and Design. Eight were undergraduates, 19 were Master's students, 13 were Doctoral students, and 2 were staff members who used to be students at the university.

\section{Materials}

The interviews explored interviewees' experiences of interacting with peers who do or do not speak the same native language. For the international interviewees, the focus was on when and how they used English in informal contexts such as class breaks, meals, or social events outside of school. We asked about their interactions with those who spoke the same native language, with speakers of other non-English native languages, and with nativeEnglish speaking American students. We also asked about the topics they talked about, how conversations were initiated, and who they turned to for task-related and other kinds of information. The question sets for American interviewees were similar but inquired about only two groups: those who speak English as a native language and those who speak it as a non-native language.

\section{Procedure}

Participants were interviewed one-on-one, in English, by the first author (a native speaker of Mandarin Chinese and fluent in English). Before the interview, participants were briefed about the purpose of the study and instructed to answer the questions according to their own personal experiences. They were then interviewed following our interview protocol. When necessary the interviewer asked follow-up questions to understand specific responses. Interviews lasted 45-60 minutes; participants were then thanked and compensated $\$ 15$ for their time.

Interviews were audio-recorded using a Olympus WS$331 \mathrm{M}$ digital recorder and transcribed using a modified version of Jefferson's [29] system, in which false starts, pauses, and other disfluencies were noted but the exact length of pauses and detailed prosodic information was not. For ease of reading, we have removed disfluencies from the excerpts presented below.

We used an iterative, grounded theory approach [24] to identify and organize recurring themes that emerged after multiple iterations of coding and analysis. During the analysis process, we first sorted the data into meaningful categories of phenomena, such as interviewees' general social activities, activities in short breaks, interaction with different groups of people, and language use in social situations. From the categories, important themes were derived and are presented in the following section.

\section{RESULTS}

Four central themes emerged that shape interaction across language boundaries among international respondents: problems in common ground and language comprehension; feelings of social obligation toward members of one's own language and culture; a desire to build rich friendships for social capital; and the positive benefits of prior structured experiences with native English speaking Americans. These themes are not mutually exclusive, or exhaustive of the themes in the transcripts, but they provide a useful framing of interviewees' experiences. Another theme, cultural awareness, emerged on the American respondents' side but was not identified by international interviewees.

\section{Common Ground and Community Co-Membership}

The first theme that ran through the interviews of nonnative English speakers revolved around what Clark and colleagues $[11,12]$ have called common ground, or shared knowledge and beliefs that help ensure that messages are understood as intended. Non-native English speakers reported three types of problems with respect to common 
ground that influence the interaction level of informal communication: idiomatic English usage, American cultural referents, and English conversational routines.

\section{Informal and Idiomatic English}

One important source of common ground is shared knowledge of a language, which for informal interaction includes idioms, jargon, and slang. Interviewees pointed out that informal English was quite different than what they had learned in formal English classes, and their lack of familiarity with idiomatic phrases was a handicap to informal (but not work) communication.

[N]ative speakers sometimes use a lot of idioms sometimes I cannot totally understand what they are saying. (I16, Taiwan)

I don't know about the slangs or English they talk between friends ... (I22, Korea)

In addition, the fast pace of informal exchanges, especially in large group settings, proved challenging to non-native English speakers.

I think I made several friends, native friends, here. And I like to talk to them but if like attending some party or some something like this ... I know it's a good chance for me to know people, talk with people. I just a little afraid ... I just see all the people around me. They're just chatting, chatting and talking, talking. Well, I just can't understand. (I1, China)

Although interactions among international students who spoke different native languages posed similar challenges for conversational grounding, interviewees reported less trouble in these interactions. Non-native English speakers found it easier to communicate in English in a group that includes other non-native English speakers, or people who are also new to the American culture. In part, this is because the playing field was leveled because all parties to the conversation were speaking in a non-native language.

[I]nternational students basically can understandEnglish is their non-native language so they try to use formal vocabularies and good expressions. (I16, Taiwan)

[For international students] English is merely a nonnative language. So there aren't really terms that are so culture-infused that we couldn't really understand between each other. So we were using really text-book English ... So they don't have much cultural references and like slangs. I think that's an important distinction between communication amongst international students and communication between American students and international students. (I26, Korea)

\section{Shared Cultural Referents}

The quote above also highlights a second important source of common ground: co-membership in a community or culture that shares certain knowledge, beliefs, and opinions [12]. For example, American college students are likely to know (and discuss) TV shows like Saturday Night Live, while students from other countries may not have heard of the show or know what it is about. Lack of cultural referents combined with language anxiety left non-native interviewees feeling "lost" in English-based social activities.

If I hang out with American students, I will feel a little bit less confident. I would think that I'm not that good in English, I'm not that good in expressing myself and I don't know much about you and I don't know what I would like to talk with you. (I20, Korea)

[J]oining conversation at a party, sometimes you need to encourage yourself to join in because they are speaking very quickly, and so they are laughing ... I want to join that kind of conversation, but my English sometimes very slow, and then ... I cannot understand their punch line, so I cannot share laughing. (I23, Japan)

Some interviewees also expressed frustration that their American peers had unrealistic expectations about the degree to which cultural referents would be shared across nations and cultures.

I have this one class ... one of the [American] students ... had an example and the rest of class were like what are you talking about? And then the [American] professor was like you have to know that and we just feel like come on we're from another country how can we know that? ... So sometimes it's just hard to communicate... sometimes you just don't know what they're talking about. (I9, China)

Even when American cultural referents were mutually understood, non-native speakers sometimes found the topics less interesting than things they might discuss with members of their own linguistic and cultural communities.

So my background is all in Chinese. It's a cultural background I don't think that can change a lot when you are grownup so it's still important to have people from your own cultural background to talk and discuss things you can share interest with ... if I come in here with American students, they will talk about movies, sports that type I'm not interested in and that's probably just because a different background. And also we might have different political views and so it's more comfortable to discuss deeper topics with people from your own country. (I6, China)

In contrast to their experiences with American students, interviewees felt that shared elements of culture between Asian countries and the experience of being an international student in America provided ready topics for conversation among international students with different native languages.

I think I am much more familiar to talk with some international student from Japan or Korea. We are all in Asia so we have similar culture ... (I24, Taiwan) 
[M] ost of my close friends are Asian, even [though] we cannot speak the same native language ... even when we communicate in English, we can understand each other easier than when we try to understand Americans. (I25, Thailand)

Within language groups, topics of conversation ranged widely from personal to purely business and had more depth in conversation content than conversations with native English speakers.

Well, seriously I haven't talked with American friends ... We just say $h i$ and ... share the greetings and how things going on and that's it. We never talk about our deeper conversation. (I16, Korea)

\section{Knowledge of Conversational Routines}

Finally, common ground includes understanding certain conversational conventions such as turn-taking rules [42] and norms for appropriate conversational content in various informal settings. Interviewees had often not learned such aspects of English in their formal language training and found it challenging to identify expectations. One source of difficulty was how to respond to formulaic questions that Americans usually answer in a routinized way (e.g., responding to how are you? with fine) rather than as a true question-answer pair.

Sometimes in daily conversation there is what's up? or how are you doing? ... at first I do not know how to respond ... like what's up? sometimes I have to think about it. (I5, China)

It's my impression, but I feel like Americans are not comfortable with silence, so they try to do small talk, and I don't really like that, because, Korean culture, we don't do small talk, like How are you? and we don't ask those things. (I33, Korea)

\section{Social Obligation}

Whereas gaps in common ground between speakers of different native languages create a kind of push away from informal interaction among Americans and international students, feelings of social obligation provide a pull toward greater interaction within a language/cultural group. Our Asian respondents, especially those who were members of relatively large language communities such as the Chinese and Korean students, reported having a strong sense that they should choose to interact with those from their own linguistic background when given the choice.

Actually, I do want to explore the opportunity to interact with foreign friends but ... there's so many Chinese students and ... they are going to say hey come sit here. Come talk with me or something like that and it's just very uncomfortable to say ok no. I do not want to talk to you today. I want to talk with some foreign friends. (I3, China)
I have to hang out with Chinese. I'm in the Association and I don't feel you are comfortable if you abandon your own people. (I4, China)

It's just much easier to get a Korean friend, and also Koreans think it's really important for Koreans together. There's the Korean community. (I30, Korea)

Although the majority of interviewees from China, Korea and Taiwan expressed this group-level motivation of social obligation, there was a small minority who were motivated to interact with Americans due to their personal ambitions and career goals of staying in the U.S.-goals that were sometimes in conflict with the pull forces of their community. For example, one participant stressed the need to acquire strong English skills for a future career.

I was trying to practice my English. That's why I mostly hung out with people [who] speak English, like people from Europe mostly. (I11, China)

Others sought experience with U.S. culture, again with future job opportunities in mind.

I want to interact with American although it's not that easy ... about career and if you want to work in here or you want to live in here you definitely want to ... you could really have some friends in here. (I24, Taiwan)

I think it's important to get exposed to diverse environment, and I'm thinking of getting a job here first so it can help me definitely. So it's more like dutiful. I feel more obliged to hang out with them and get used to their culture, but like personally and emotionally not really. (I29, Korea)

These attempts to reach out across cultures and languages were not always viewed positively by other members of the same language community.

There are definitely some people [who interact with Americans]. I will not be like that ... Well, like my friend in the class, that particular girl who likes to hang out with Americans. I believe she has a task. That's her responsibility to bridge those gaps. It's not mine $<$ laughter>. (I4, China)

Interviewees who were members of small campus language communities, such as the Japanese, Nepalese, or Indonesian interviewees, reported being more open to mingling with people from other linguistic and cultural backgrounds, most likely because they did not have a large in-group toward which they felt strong social obligations.

Thai students ... have pot luck party about twice per semester. So I not meet them that often. I think part of the reason is because I am the only one Thai [college name] student and $80 \%$ of Thai students are undergrad students. So they hang out a lot together ... And other $20 \% \ldots$ they don't hang out at all. (I25, Thailand) 


\section{Social Network and Relationship Development}

In addition to reporting feelings of social obligation toward those with whom they already had established ties, our non-native English speaking interviewees were concerned with building new social networks and developing social capital. Many came to the U.S. knowing few other people, and strove for both bonding social capital that provided emotional support and bridging social capital that could enhance their future career prospects [40].

\section{Building Bonding Social Capital}

Because of concerns about being able to converse fluently with Americans, non-native speakers rarely initiated social talk with their American classmates or friends. In some cases, they avoided going to English-language social events altogether. Consequently, they saw little commonality that could be used to build relationships with American peers. Instead, they put effort into making new friends within their own language group, through a variety of informal social activities and campus organizations.

When I first came to [school], I didn't know a lot of Koreans around campus, but I started to go to church group, and I also worked for Korean Grad Student Association, so I got to know more Koreans, and I feel more comfortable being with them, because we speak same language, and we share the similar culture (I33, Korea)

Our interviewees pointed out that they found it difficult to share similar experiences with their American peers, because Americans and Western European students preferred different types of social activities.

A lot of Americans, they just want to go for a drink, but I don't like to drink alcohol so if they wanted to go clubbing or go to bars, I just don't want to go because I don't like to drink. (I18, Taiwan)

Furthermore, since free time was short, interviewees felt that they had to focus their relationship-building efforts where they were most likely to succeed:

So it needs time to build the relationship. And it's not easy to build relationship with everyone. So ... you have limited people that you can approach, and you not see them all the time. (I25, Thailand)

\section{Building Bridging Social Capital}

Bridging social capital consists of ties between people in heterogeneous groups that are more useful for information exchange than emotional bonding [40]. The types of bridging ties our interviewees sought were linked to their individual career aspirations. For those hoping to stay in the U.S. after graduating, ties with Americans were highly valued:

I think you have to seek the chance to interact with people from other origins just to broaden your view or just to build up your experience. And maybe the next time you get the chance to talk about ... in business ... I think those are valuable experiences. (I3, China)
These interviewees, who were usually from professional schools such as Law, International Relationships, Business, or Human Resources, were more likely to attend English language social events because they actively sought job opportunities in the U.S. or they needed to learn how to deal with people of different cultures to meet the requirements of their desired job.

[I]f I want to work in Human Resources, especially in a globalized companies it's very important to know people from different countries not just in U.S. or other European countries so I think it's really essential ... (I17, Taiwan)

For others, who hoped to return to their home country after a perhaps lengthy absence, bridging ties with members of their own linguistic community offered not only bonding connections in the present but also paved a way leading to the future after they return.

[C]ommunicating with these people from China definitely help me to have better knowledge of the current situation in China right now. Because I'm thinking about going back to China eventually some time and I will definitely spend time trying to adapt to the environment there then and since I've been outside of China for so long and that's going to take some time and these are definitely going to help me. (I11, China)

Students from larger same-language groups thus had choices about who to interact with and why, and tensions between group cohesion and expanding networks, bridging and bonding, shaped people's choices. Students from smaller same-language groups had less choice: their willingness - and need - to interact with people from other linguistic backgrounds also pushed them to expand their social networks, and to reach out more than other students.

I try to make opportunities, "Oh, this is good weather," very simple topic. <laughs> I mean, otherwise, yeah, everybody is just focusing on research or classes. I'm sharing with three people, yeah, American people and Canadian people. But they're just focusing on studies or ... few don't say anything, just no conversation, and then that's it, so I try to make opportunity to, "Hey, how it's going?" (I23, Japan)

\section{Prior Experience in Structured Contexts}

While uniformly agreeing that it was difficult to build new friendships with native English-speaking Americans, our interviewees did provide some insights into when these friendships were most likely to flourish. Three interactionlevel factors in particular were mentioned throughout the interviews as supportive of relationship-building across language boundaries: physical proximity, one-on-one or small-group interaction, and an established work relationship. 


\section{Physical Proximity}

International interviewees said that being in the same environment supported building social relationships, just as it does within English speaking communities [22, 51].

I think it usually starts with a class, when I take classes with [native English speakers]. And all of my close international friends were in choir, which had a really social and close atmosphere, so we had more opportunities to talk to each other rather than academic classes. And because it's a music class it we have a common topic to start a conversation, so that was a beginning part. And I think conversations just lead us through a closer relationship. (I29, Korea)

Unfortunately, however, these relationships often did not outlast the time the individuals were collocated:

I used to share my office with other Americans in this department, but my office changed last semester, but, when I was spending most of time there, I was around Americans all the time and we had a lot of conversations about professors, yeah ... it helps a lot. It gives me more a chance to speak with [American students], and that's makes me more comfortable speaking with them, and I eventually hang out with them later after work, and I used to go ski, snowboarding with my office American mates. But, after moving my office, I feel really distant from them, cause of less interaction. (I33, Korea)

\section{One-on-One Interactions}

Our non-native English speaking respondents felt it was easier to get to know native English speakers when conversation was one-on-one or in small groups. In a social setting with many native speakers and simultaneous conversations, the non-native speakers found it hard to participate. They also felt their English-speaking partners were more attentive to their needs in one-on-one settings.

So if I hang out with my American classmates, if we go out in a group then I would be more unlikely to speak because they'll do most of the talking themselves but if I hang out just one or two of them and then I have more room to express myself and then they'll just listen and it's easier for me to communicate with just one or two of them ... (I19, Taiwan)

\section{Established Work Relationships}

Respondents also suggested that relationships were more likely to develop when people worked together on a project, because the mutual knowledge provided through work could form the basis for conversation.

I need to order something. Or our equipment is broken. So I have to go to a technician talk about how this could happen or could you draw something for me ... And well he's the one that wants to talk but he won't come to you and say hey I want to talk to you. It's like you come to him and say something and you just start talking. So it's like during the repairing stuff for whatever he will be like oh what do you think of this blah blah blah or that blah blah blah. Or sometimes we will talk about vacations stuff like that. (I9, China)

\section{Native English Speakers' Viewpoints}

We now turn to the interviews with native Englishspeaking Americans. In our analysis, we sought to identify the extent to which the themes developed based on interviews with non-native speakers could also be found in the interviews with native speakers. Our data suggest that many, but not all, of the push and pull forces that influence interaction across language barriers are shared by all members of multilingual organizations. Given that the emergent themes for native and non-native speakers only partially overlapped, we chose to juxtapose rather than merge their viewpoints. This allows us to explore each group's perspective independently, without being constrained to only the overlapping themes. The data also show some awareness among the English speaking majority of the challenges faced by non-native speakers.

\section{Common Ground and Community Co-membership}

Native speakers did not consider the language proficiency of non-native speakers as a serious issue in informal communication. But they echoed the non-native speakers' points about a lack of shared common ground derived from cultural membership. The native speakers saw this lack of common ground as a barrier to initiating conversation with non-native speakers.

It might be easier to make friends with Americans more quickly than it might be for international students, because I think we'll have more superficial things in common ... for example, if I'm from the Midwest in the United States, Ohio, and my friend's from Michigan, you know, that's a kind of superficial thing, like there's a rivalry between my school and his school, and so like we beat you in football, blah, blah, blah. And like those superficialities make it easier to like instigate conversation. Whereas if I meet someone from like Nepal, I don't know anything about Nepal. I can't say my school beat your school in football. (I36, US)

The native speakers also expressed awareness that American cultural norms and referents might be problematic for non-native speakers, making it harder for them to understand informal English conversations.

So there's language proficiency, but there are a lot of cultural nuances as well when you talk [to] people from another culture (I42, US).

Some native English speakers expressed awareness that communicative norms differed and some understanding of factors (age, status, etc.) that guide those norms.

In terms of age and hierarchy a lot of international people that I know are much more sensitive to the subtleties and hierarchy. And in terms of respect and authority, they have a greater sensitivity in their 
behavior, and language, and body language to all of those issues. (I36, US)

When [international students] talk to American students they don't expect them to know anything about Chinese culture or Chinese language. So the fact that this is something that I've been studying for a while and just something that I've accumulated through self-interest like my ability to sort of like throw out facts really I guess engenders me to them. They're like, "Oh hey, this is a guy that I can say stuff and he'll understand it. I don't have to like try to pretend to be an American student to him. He's pretending to be a Chinese student to me it's a lot easier for me." (I40, US)

\section{Social Obligation}

American interviewees did not report feeling that they had obligations to any specific group members, in the way that non-native speakers reported feeling obligated toward fellow speakers of their native language. Most likely, this is because the native English speakers were in the majority in almost all contexts within the organization, and thus speaking to another native English speaker would not seem like an active choice but rather the norm. In addition, none of our native English speaking interviewees seemed to have considered that social obligation might be important to their non-native colleagues.

\section{Social Network and Relationship Development}

Native English speakers also did not raise issues of social network development as either an impetus or a barrier to interaction across language barriers. It is possible that most of the individuals who the native English interviewees would think of in this regard are also native English speakers (professors, senior students, alumni) so there was no conflict with their default patterns. They likewise did not seem to consider that this would be an important factor for non-native speakers.

\section{Prior Experience in Structured Contexts}

Our non-native speaking interviewees suggested that physical proximity, one-on-one interactions, and structured relationships were factors that increased the probability of interaction across language barriers. Some of these factors were also noted by the English speaking interviewees, especially as regards to the effects of physical collocation.

Generally, because we're in a university environment, we can talk about [non-native English speaking acquaintances'] classes and what they're interested in doing, and that gets you a lot of mileage right there, because there's a lot of things to talk about. Or people's experiences with a certain class, how they did, how they felt about that, did they understand that concept, da da da. So I'd say that's the most common thing. (I37, US)

I think a lot comes out in conversation at dining halls. Like you don't have anything really to talk about ... Eventually you'll talk about where are you from, and like what did you do before [this university]. And so I think like, especially in my dorm on my floor, like we would all go to dining halls together as a group. So I think like you find out a lot about the group like just in informal conversation, like just people talking back and forth to each other, like trying to get to know each other and stuff. (I41, US)

The English speaking interviewees also showed some realization that the ideal structures for interaction might vary between native and non-native speakers.

Some of [my Chinese friends] told me that they really valued one-on-one time. If you go somewhere with a friend, and you pay attention to them, then that's something that's very valued. But if you say, "Hey, come to this party. There'll be 30 people there." Then I think especially because this friend was not very good with English, he didn't really wanna come to a large group hangout, because he thought he would just kind of get lost in the background (I42, US).

\section{DISCUSSION}

In this paper, we used a grounded theory approach to explore experiences of native and non-native speakers in English-speaking informal settings. We found that nonnative speakers showed a strong preference for interacting informally within their own language community rather than across language boundaries. This is consistent with the language clustering Tange and Lauring observed in a Danish multinational firm [49], suggesting that this kind of clustering is not unique to the academic environment, or to specific language communities.

We identified several factors that influenced how nonnative English speakers interact within or across language groups. Interaction-level problems like how to establish common ground, especially with respect to English slang and American cultural referents, made it hard for nonnative speakers to engage in informal communication with native English speakers. While all non-native interviewees passed the minimum standard of language proficiency test set by the school, colloquial English doesn't always resemble the usage or vocabulary the students' learned in preparation for studying abroad. In other words, fluency or a high spoken test score does not indicate comfort and smoothness in informal communication. Non-native speakers expressed a lack of confidence in colloquial English, leading them to prefer spending meals, breaks, and other unstructured time with other members of their own language community.

Moreover, group-level factors could contribute to this clustering effect. The number of other students on campus speaking one's native language, accompanied with a sense of social obligation to this language community, influenced how much emphasis non-native speakers placed on building relationships within their own language community versus across language communities. Nonnative speakers also expressed a tradeoff between building 
relationships within and beyond their own language community, consistent with Ying's [56] findings that Taiwanese students considered social capital to be a finite resource. This preference for interaction within one's own language community, however, was not universal. Seeking to expand one's social network as an individual-level factor drives those with a greater motivation to stay in the U.S. after graduation, or who were members of small language communities, to try to develop friendships with Americans.

Although issues of common ground and the desire for social relationships within one's own language community worked against informal interaction across language boundaries, there were four factors of different levels that increased the likelihood of informal interaction between our non-native English speaking interviewees and native English speaking Americans. Other than an individual's pursuit of a career in the U.S,, on the interaction level, nonnative speakers found it easier to establish relationships with Americans if they were physically close (e.g. adjacent offices), or if there was a formal work relationship (e.g., lab mates). On the group level, non-native speakers tend to socialize more across groups if group size was very small.

For the native English speakers, one factor that influenced their interaction with non-native speakers was a lack of "cultural common ground," or a shared understanding of appropriate conversational topics and interactional processes in other cultures. To some extent, however, they felt that these problems could be reduced through better cultural awareness. Such awareness does not mean a full grasp of cultural norms from other countries; instead, it is a recognition and understanding that there may be different norms, and where these differences are most likely to arise. Adaptations followed by cultural awareness, such as acting according to non-native speakers' familiar way, can help interaction with non-native speakers.

Despite an awareness of possible cultural barriers, native English speakers might not be aware of the profoundness of the language issues faced by non-native speakers and how these issues might impede potential interaction. Like the non-native speakers, native English interviewees also thought that having structured interactions, such as working on the same group project or being members of the same lab, made it easier to interact across language communities.. Possible adaptations like prompt detection of miscommunication by offering explanations of cultureridden referents, slowing down while talking in groups, or using fewer idioms, can alleviate non-native speakers' language issues.

Although we did not directly measure the outcomes of linguistic clustering on non-native English interviewees' participation in the English language academic community, we can surmise from previous research [e.g., 30] that this lack of informal interaction across language groups will influence important organizational processes, including the development of new collaborations, informal awareness of colleagues' activities, and information exchange.

One implication of our results is that organizations need to think carefully about their informal relationship-building activities. For example, in one department studied in this paper with a very large number of graduate students from Asia, the faculty organized a large weekly get together at a local bar. According to our interviewees, this is precisely the type of event at which clustering, rather than informal interaction across language barriers, is likely to occur.

\section{Tool Support for Informal Interaction}

In addition to more carefully chosen opportunities for faceto-face interaction within an organization, $\mathrm{CMC}$ tools play an important role in both work and educational multilingual contexts. In work contexts, CMC tools are used to facilitate geographically distributed teams $[15,32$, 45]. In educational contexts, CMC tools for online learning such as Blackboard, Moodle, and Piazza are increasingly used to complement classroom instruction [46]. Further, evidence suggests that non-native speakers often prefer CMC to face-to-face interaction [e.g., 44, 46].

Thus, CMC tool design may allow global organizations to help non-native speakers be more comfortable and more effective members. This does not mean that systems should enforce cross-lingual interaction: although effective communication and diverse participation can be important for both the organization and the long-term success of individual members, participants often had values that led them to interact with same-culture and same-language partners. Instead, our goal is to support these values and encourage people to reflect on them, while mitigating barriers to cross-lingual interaction such as the lack of shared cultural referents or awareness of language difficulties that participants highlighted.

We structure our discussion around barriers at the level of choosing cultural groups, of fostering individual relationships, and of supporting particular interactions.

\section{Groups: Facilitating Awareness of Culture}

At the level of social groups, our non-native English speaking interviewees said it was easier to communicate with fewer participants, more room to talk, and more attention devoted to the conversation. CMC tools could partially recreate these conditions by manipulating either the composition or the perception of group sizes. Familiar examples include supporting parallel conversations in discussion and chat spaces through providing separate topics, as in Babble [20]. The Mad Hatter system [4] helped participants experience large physical gatherings as a set of smaller, more manageable conversations, while Talking in Circles does a similar job in a virtual space [41]. A number of techniques, including subgrouping, recommendations, filtering, and awareness interfaces, can help CMC tools create more intimate and attentive environments to support cross-lingual communication. 
But participants didn't just want subgroups: they wanted subgroups that met relational goals and fulfilled social obligations. Sometimes this meant reaching across languages or cultures, but other times it required supporting the same-culture community. Thus, recommendation tools seem less appropriate than tools that support awareness of others' linguistic and cultural backgrounds. Especially in dynamic environments, social proxies [20] augmented with such information might help people in a multilingual organization quickly see groups, topics, and places where people of different backgrounds are most active, allowing them to make choices that suit their current goals.

CMC tools might also encourage people to reflect on these goals and obligations by providing aggregate views of their interaction history with people of different linguistic and cultural backgrounds. Since such activity data is more useful with information to help interpret it [32], the tool might also explicitly present information about the value of bilingual networks for building bridging social capital in organizations [2] and provide indicators of this capital. Following the lead of the Search Dashboard, which used comparisons to expert behavior to guide searchers [5], systems might also present the interaction history and social network of successful peers or leaders in the organization as points of comparison to support reflection and suggest behavior.

\section{Individuals: Supporting Relationship Development}

At the level of individual relationships, interviewees said that a structured work context helped them develop knowledge about each other, facilitating more natural and spontaneous informal conversation. CMC tools might help create shared contexts, referents, and structures for conversation in a number of ways. Recommender systems might play a useful role here, as part of a virtual buddy system that augments existing language partner matching programs on campuses by recommending other-language partners with shared interests. This would likely increase their chance of having common ground for mutually interesting and understandable conversation. Such a system might be especially useful for members of minority cultural groups such as our Thai and Indonesian participants, who had to reach out beyond their own community because of a lack of numbers.

The communication channel itself might help structure activities and provide referents. Shared activities at a distance, such as physical exercise [38], might work as icebreakers that help people cross language and cultural barriers by both structuring and constraining interactions. The channel might also organize conversation around artifacts that serve as shared referents, as in the SocialTV system's use of television shows as a platform for social activity [19]. Online educational tools also often structure group activities around specific topics, and the combination of collaborative learning and social presence leads to satisfying outcomes for students [46]. Further, in both educational and icebreaker contexts, interaction partners are often chosen by an external authority such as the teacher or host. CMC-enabled icebreakers and training tools can also delegate partner choice to the system, perhaps reducing feelings of social obligation while allowing organizations to encourage cross-lingual interactions.

CMC tools might also manipulate features of the channel to create feelings of social presence and proximity that might elicit greater informal interaction across language groups, based on our participants' own experiences of the value of proximity. For instance, abstract representations of presence [e.g., 20, 41] or actual video-conferencing [e.g., 30] may both increase this sense of presence.

\section{Interactions: Enhancing Grounding and Empathy}

At the level of individual conversations, non-native speakers needed help with cultural references and colloquial language. Systems might provide information relevant to current context such as status updates, IM conversations, or emails in order to build this common ground. For instance, IdeaExpander extracted keywords from an IM conversation to retrieve pictures that supported multi-cultural brainstorming [52]. Displaying a collage of pictures and text relevant to ongoing conversation might contextualize cultural referents and provide information to help resolve ambiguity, translation errors, and other fluency issues. Another way to address fluency issues would be to exploit real-time machine translation tools that allow people to converse in their native languages $[54,55]$. And, though we have focused on $\mathrm{CMC}$, physical spaces might also be augmented with a combination of speech recognition and ambient displays to present icebreakers and conversational referents.

Native speakers were aware of these cultural differences, but were relatively insensitive to language difficulties even though these were a major problem for non-native speakers. Techniques that analyze the conversation and present information about potential difficulties might help people realize and react when fluency issues are affecting an interaction. This idea is based on earlier systems that displayed relative levels of activity in a group conversation, leading participants to change their speaking behavior [16] and reflect on the conversation [5]. To address potential barriers to fluent conversation, systems might measure the rate of speech, rate of topic changes, presence of idiom and slang, measures of formality or reading level, and other indicators of linguistic complexity. Presenting these metrics along with target or typical values of these indicators for native and non-native speakers could help raise awareness of both specific problematic moments and the general need to be sensitive to linguistic ability. The design would need to present this data in a way that doesn't reflect badly on non-native speakers, but done well it might lead to more sensitive and effective cross-lingual interaction. 


\section{LIMITATIONS AND FUTURE DIRECTIONS}

One of the limitations of the study is that the interviewees were recruited from a university, which while culturally diverse is relatively homogenous in terms of age and occupation and does not draw from all cultures equally. In particular, we focused on the experiences of members of the most common language communities, so we can provide no insights into the experiences of speakers of other languages such as Arabic, which are sizeable communities in many global organizations. In addition, as the study was conducted at a university, the results cannot be automatically generalized to other organizational settings. To address this limitation, we plan to follow up this work with a more extensive interview and survey study in a corporate environment that includes a greater diversity of language communities.

In addition, we used English for all of our interviews because we wanted to ensure consistency in the semistructured interview process. We don't think that the language used in the interviews strongly affected the results because all interviewees self-identified as fluent in English, and they were all used to using English in similar contexts as students in the U.S. We also conducted a pilot study in Mandarin with native Mandarin speakers while we were developing the interview protocol. Interviewees using Mandarin reported themes and experiences almost identical to those reported by our study interviewees using English.

Furthermore, because we only interviewed people in an American English-speaking organization, we cannot speak to the experiences of non-native speakers in organizations that use other languages as their lingua franca, or which are situated in other countries. We are currently conducting a parallel study of native and non-native Mandarin speakers studying in Taiwan in order to tease apart these issues.

Finally, for most of our interviewees, language and culture were inextricably intertwined and it can be difficult to identify which problems arise from cultural differences and which arise from language barriers and how language proficiency might help with cultural familiarity. To the extent that members of a variety of cultures and language groups expressed similar sentiments regarding inter-lingual interaction, however, we hope that we have captured general experiences of being a non-native speaker rather than specific characteristics of an interviewee's cultural background. To try to disentangle culture from language, future interview studies might include participants who were more or less fluent in English while holding cultural background and experience in the U.S. constant.

\section{CONCLUSION}

This study examined the factors that affect informal communication between speakers of different native languages who are members of a single large English speaking organization. Our findings indicate several forces that push people away from interaction across language boundaries, such as problems in conversational grounding, social obligations towards members of one's own language community, and the desire to develop relationships with people who speak the same native language. The findings also suggest that certain factors promote greater interaction across language boundaries, including physical proximity and structured interactions with native English speakers. Tools that provide structure and presence with support for awareness of others' linguistic and cultural background may be a promising approach for supporting informal interaction in multi-lingual organizations.

\section{ACKNOWLEDGMENTS}

This research was funded in part by National Science Foundation grant \# 1025425. The material is also based in part on work supported by the National Science Foundation, while Susan Fussell was working at the Foundation. Any opinion, findings, and conclusions or recommendations expressed in this material are those of the authors and do not necessarily reflect the views of the National Science Foundation. We thank Lydia Wright and Sarah Sanders for their assistance transcribing the interviews.

\section{REFERENCES}

1. Adair, W. L., Okumura, T., \& Brett, J. M. (2001). Negotiation behavior when cultures collide: The United States and Japan. Journal of Applied Psychology, 86, 371-385.

2. Andersen, H., \& Rasmussen, E. (2004). The role of language skills in corporate communication. Corporate Communication: An International Journal, 9, 231-242.

3. Anwati, D., \& Craig, A. (2006). Behavioral adaptation within cross-cultural virtual teams. IEEE Transactions On Professional Communication, 49, 44-56.

4. Aoki, P. M., Romaine, M., Szymanski, M. H., Thornton, J. D., Wilson, D., \& Woodruff, A. (2003). The mad hatter's cocktail party: a social mobile audio space supporting multiple simultaneous conversations. In Proceedings of CHI 2003, 425-432.

5. Barner-Rasmussen, W., \& Bjorkman, I. (2007). Language fluency, socialization and inter-unit relationships in Chinese and Finnish subsidiaries. Management and Organizational Review, 3, 105-128.

6. Bateman, S., Teevan, J., and White, R. W. (2012). The search dashboard: how reflection and comparison impact search behavior. In Proceedings of CHI 2012, 1785 - 1794.

7. Bergstrom, T., and Karahalios. K. (2007). Conversation Clock: Visualizing audio patterns in co-located groups. In Proceedings of HICSS 2007, 78.

8. Bernstein, M. S., Marcus, A., Karger, D. R., \& Miller, R. C. (2010). Enhancing directed content sharing on the web. In Proceedings of CHI 2010, 971-980.

9. Charles, M., \& Marschan-Piekkari, R. (2002). Language training for enhanced horizontal communication: A challenge for MNCs. Business Communication Quarterly, 65, 9-29. 
10. Chevrier, S. (2003). Cross-cultural management in multinational project groups. Journal of World Business, 38, 141-149.

11. Clark, H. H., \& Brennan, S. E. (1991). Grounding in Communication. In L. B. Resnick, R. M. Levine \& S. D. Teasley (Eds.), Perspectives on Socially Shared Cognition (pp. 127-149). Washington, DC: APA.

12. Clark, H. H., \& Wilkes-Gibbs, D. (1986). Referring as a collaborative process. Cognition, 22, 1-39.

13. Constant, D., Sproull, L., \& Kiesler, S. (1996). The kindness of strangers: The usefulness of electronic weak ties for technical advice. Organization Science, 7, 119-135.

14. Cramton, C. D. (2001). The mutual knowledge problem and its consequences in geographically dispersed teams. Organization Science, 12, 346-371.

15.DeSanctis, G., \& Monge, P. (1998). Communication processes for virtual organizations. Journal of Computer Mediated Communication, 3(4).

16. DiMicco, J. M., Pandolfo, A., and Bender, W. (2004). Influencing group participation with a shared display. In Proceedings of CSCW 2004, 614-623.

17. DiStefano, J. J., \& Maznevski, M. L. (2000). Creating value with diverse teams in global management. Organizational Dynamics, 29, 45-61.

18. Dubé, L., \& Paré, G. (2001). Global Virtual Teams. Communications of the ACM, 44(12), 71-73.

19. Ducheneaut, N., Moore, R. J., Oehlberg, L., Thornton, J. D., \& Nickell, E. (2008). SocialTV: Designing for distributed, social television viewing. International Journal of Human-Computer Interaction, 24, 136-154.

20. Erickson, T., Smith, D., Kellogg, W., Laff, M., Richards, J. \& Bradner, E. (1998). Socially translucent systems: Social proxies, persistent conversation and the design of "Babble." In Proceedings of CHI 1998, 7279.

21.Feely, A.-J., \& Harzing, A. W. K. (2003) Language management in multinational companies. CrossCultural Management: An International Journal, 10, 37-52.

22. Festinger, L., Shachter, S., \& Back, K. (1950). Social Pressures in Informal Groups. NY: Harper.

23. Gibbs, J. L. (2009). Culture as kaleidoscope: navigating cultural tensions in global collaboration. In Proceedings of ICIC 2009, 89-98.

24. Glaser, B. G., \& Strauss, A. L. (1967). The Discovery of Grounded Theory: Strategies for Qualitative Research. New York: Aldine de Gruyter.

25. Harzing, A-W., \& Feely, A. J. (2008). The language barrier and its implications for HQ-subsidiary relationships. Cross-cultural Management: An International Journal, 15, 49-61.
26. Henderson, J. K. (2005). Language diversity in international management teams. International Studies of Management and Organization, 35, 66-82.

27.Hinds, P. J., \& Mortensen, M. (2005). Understanding conflict in geographically distributed teams: The moderating effects of shared identity, shared context, and spontaneous communication. Organization Science, 16, 290-307.

28. Jarvenpaa, S. L., \& Leidner, D. E. (1999). Communication and trust in global virtual teams. Organization Science, 10, 791-815.

29. Jefferson, G (1984). Transcript notation. In J. M. Atkinson and J. Heritage (Eds.) Structures of Social Action: Studies in Conversation Analysis. Cambridge: Cambridge University Press.

30.Kirk, D. S., Sellen, A. \& Cao, X. (2010). Home video communication: Mediating 'closeness'. In Proceedings of CSCW 2010, 135-144.

31. Kraut, R., Egido, C., \& Galegher, J. (1990). Patterns of Contact and Communication in Scientific Research Collaborations. In J. Galegher, Kraut, R., \& Egido, C. (Ed.), Intellectual Teamwork. Hillsdale, NJ: LEA.

32. Leshed, G., Cosley, D., Hancock, J. T., and Gay, G. (2010). Visualizing language use in team conversations: designing through theory, experiments, and iterations. In Proceedings of CHI 2010, 4567-4582.

33. Lipnack, J., \& Stamp, J. (1997). Virtual Teams: Reaching Across Space, Time and Organizations with Technology. NY: John Wiley \& Sons.

34.Luo, Y., \& Shenkar, O. (2006). The multinational corporation as a multilingual community: Language and organization in a global context. Journal of International Business Studies, 37, 321-339.

35. MacIntyre, P. D., Noels, K. A., \& Clement, R. (1997). Biases in self-ratings of non-native language proficiency: The role of language anxiety. Language Learning, 47, 265-287.

36. Massey, A., Montoya-Weiss, M., Hung, C., \& Ramesh, V. (2001). When culture and style aren't about clothes: Perceptions of task-technology "fit" in global virtual teams. In Proceedings of Group 2001, 207-213.

37. Morris, M. W., Podolny, J., \& Sullivan, B. N. (2008). Culture and coworker relations: Interpersonal patterns in American, Chinese, German, and Spanish divisions of a global retail bank. Organization Science, 19, 517532.

38. Mueller, F., Agamanolis, S., \& Picard, R. (2003). Exertion interfaces: sports over a distance for social bonding and fun. In Proceedings of CHI 2003, 561568.

39. Olson, G. M., \& Olson, J. S. (2000). Distance matters. Human Computer Interaction, 15, 139-178. 
40.Putnam, R. (2000). Bowling alone: The collapse and revival of American community. NY: Simon and Schuster.

41. Rodenstein, R., \& Donath, J. S. (2000). Talking in circles: Designing a spatially-grounded audioconferencing environment. In Proceedings of $\mathrm{CHI}$ 2000, 81-88.

42. Sacks, H., Schegloff, E., \& Jefferson, G. (1978). A simplest systematics for the organization of turn-taking for conversation. Language, 50, 696-735.

43. Sarbaugh-Thompson, M., \& Feldman, M. S. (1998). Electronic mail and organizational communication: Does saying "hi" really matter? Organization Science, 9, 685-698.

44. Setlock, L. S., \& Fussell, S. R. (2010). What's it worth to you? The costs and affordances of CMC tools to Asian and American users. In Proceedings of CSCW 2010, 341-350.

45. Shachaf, P. (2008). Cultural diversity and information and communication technology impacts on global virtual teams: An exploratory study. Information Management, 45, 131-142.

46. So, H.-J., \& Brush, T. A.. (2008). Student perceptions of collaborative learning, social presence and satisfaction in a blended learning environment: Relationships and critical factors. Computers \& Education, 51, 318-336.

47. Takano, Y., \& Noda, A. (1993). A temporary decline of thinking ability during foreign language processing. Journal of Cross-Cultural Psychology, 24, 445-462.

48. Takano, Y., \& Noda, A. (1995). Interlanguage dissimilarity enhances the decline of thinking ability during foreign language processing. Language Learning, 45, 657-681.

49. Tange, H., \& Lauring, J. (2009). Language management and social interaction within the multilingual workplace. Journal of Communication Management, 13, 218-232.

50. Tietze, S. (2004). Spreading the management gospel-in English. Language \& Intercultural Communication, 4, 175-189.

51. Veinott, E., Olson, J., Olson, G., \& Fu, X. (1999). Video helps remote work: Speakers who need to negotiate common ground benefit from seeing each other. In Proceedings of CHI 1999, 302-309.

52. Wang, H-C., Fussell, S. R., \& Cosley, D. (2011). From diversity to creativity: Stimulating group brainstorming with cultural differences and conversationally-retrieved pictures. In Proceedings of CSCW 2011, 265-274.

53. Yashima, T. (2002). Willingness to communicate in a non-native language: The Japanese EFL context. The Modern Language Journal, 86, 54-66.

54. Yamashita, N., \& Ishida, T. (2006). Effects of machine translation on collaborative work. In Proceedings of CSCW 2006, 515-523.

55. Yamashita, N., Inaba, R., Kuzuoka, H., \& Ishida, T. (2009). Difficulties in establishing common ground in multiparty groups using machine translation. In Proceedings of CHI 2009, 679-688.

56. Ying, Y-W. (2002). Formation of cross-cultural relationships of Taiwanese international students in the United States. Journal of Community Psychology, 30, 45-55. 